\title{
Aldoxorubicin: a tumor-targeted doxorubicin conjugate for relapsed or refractory soft tissue
} sarcomas

This article was published in the following Dove Press journal:

Drug Design, Development and Therapy

\author{
Jun Gongl,* \\ Jessica Yan ${ }^{2, *}$ \\ Charles Forscher ${ }^{3}$ \\ Andrew Hendifar ${ }^{4}$
}

'Department of Medical Oncology, City of Hope National Medical Center, Duarte, CA, USA; ${ }^{2}$ Department of Hematology and Oncology, HarborUCLA Medical Center, Torrance, CA, USA; 3 Sarcoma Program, Samuel Oschin Cancer Center, Cedars-Sinai Medical Center, Los Angeles, CA, USA; ${ }^{4}$ Gastrointestinal and Neuroendocrine Malignancies, Samuel Oschin Cancer Center, Cedars-Sinai Medical Center, Los Angeles, CA, USA

*These authors contributed equally to this work
Correspondence: Andrew Hendifar Gastrointestinal and Neuroendocrine Malignancies, Samuel Oschin Cancer Center, Cedars-Sinai Medical Center, 8700 Beverly Boulevard, AC 1042C, Los Angeles, CA 90048, USA

$\mathrm{Tel}+\mathrm{I} 3104232217$

Fax + I 3109678486

Email andrew.hendifar@cshs.org

\begin{abstract}
Despite available therapies after initial systemic therapy, prognosis remains poor in relapsed or refractory soft tissue sarcomas (STS). The rational and clinical development of novel agents to improve outcomes in this area of high unmet need is desperately warranted. Aldoxorubicin is a prodrug of doxorubicin that binds to serum albumin immediately after administration through an acid-sensitive hydrazone linker and is subsequently transported to tumor tissues where the acidic environment cleaves the linker and facilitates delivery of a tumor-targeted drug payload. In clinical studies to date, there has been evidence of efficacy and mitigated cardiac toxicity. In this review, we comprehensively detail the clinical development of aldoxorubicin in STS to date. Specifically, we highlight available data on the pharmacokinetics and efficacy from Phase I, Phase II, and Phase III trials in advanced or metastatic STS. We conclude with considerations for future directions of investigation for this promising antitumor agent.
\end{abstract}

Keywords: aldoxorubicin, albumin conjugate, soft tissue sarcomas, clinical trials, pharmacokinetics, cardiotoxicity

\section{Introduction}

Soft tissue sarcomas (STS) comprised a biologically heterogeneous group of malignancies with $>50$ subtypes. ${ }^{1}$ Collectively, STS are relatively rare and account for $<1 \%$ of adult cancers with an estimated 12,390 new cases in the USA in $2017 .^{2}$ Approximately $50 \%$ of patients with high-grade STS develop metastatic diseases, and the median overall survival (OS) for advanced or metastatic STS has ranged from 12 months (historical) to $18-19$ months (contemporary). ${ }^{1}$ For a select group of sarcomas including gastrointestinal stromal tumors (GISTs), innovative and histologyspecific targeted therapies are available. ${ }^{3-12}$ However, for the majority of advanced STS, of which the most common high-grade subtypes include undifferentiated pleomorphic sarcoma (UPS), liposarcoma (LPS), leiomyosarcoma (LMS), synovial sarcoma (SS), and malignant peripheral nerve sheath tumors (MPNSTs), anthracycline (eg, doxorubicin)-based systemic therapy remains the standard first-line therapy. ${ }^{1}$

Dose-intensive combination chemotherapy with doxorubicin and ifosfamide (AI) with granulocyte colony-stimulating factor (GCSF) support is a currently favored approach in the initial or first-line treatment of advanced or unresectable STS in patients with good performance status (PS) and particularly when there is a need to relieve acute symptoms or for tumor debulking prior to surgery or radiation therapy.${ }^{13-16}$ Although no OS benefit was demonstrated between first-line doxorubicin and AI in a Phase III randomized trial, several factors could have affected the lack of an OS difference. ${ }^{13}$ 
The study required enrollment of patients having confirmed unresectable or metastatic disease progression within 6 weeks of treatment that may have excluded a number of patients with high-grade STS that would have potentially benefited from combination therapy. The first randomization occurred in 2003, and survival analysis for this trial was still ongoing at the time of publication in 2014. The effect of postprotocol treatment on survival was not assessed but potentially could have impacted OS in both cohorts. ${ }^{13}$ Nevertheless, recommendations for AI in this population have been supported based on significantly improved progression-free survival (PFS) and overall response rates (ORRs) with combination therapy, though often at the expense of increased adverse events (AEs), when compared with control arms. ${ }^{13-16}$ More recently, the combination of doxorubicin and olaratumab (anti-platelet-derived growth factor receptor [PDGFR] antibody) was approved by the US Food and Drug Administration (FDA) for anthracycline-naive locally advanced, unresectable, or metastatic STS and represents another option in the front-line setting that should be considered in those with $\operatorname{good}$ PS. ${ }^{17}$

In patients with unresectable or metastatic STS who are less fit and for whom therapy is palliative to control metastatic diseases, sequential single-agent chemotherapy with doxorubicin, ifosfamide, or liposomal doxorubicin $\left(\right.$ Doxil $\left.^{\circledR}\right)$ is often recommended, given the likely lower toxicity without significant impairment in survival associated with this approach. ${ }^{1,18-20}$ Significant improvements in outcomes (ORR, PFS, and OS) are still seen in previously treated patients with advanced or unresectable STS and good PS; in particular, clinical benefit was seen when modern therapies (single-agent or combination therapies developed during the trabectedin era) were compared with older, conventional agents or best supportive care after failure of first-line therapies. ${ }^{21}$ In the modern era, therapies after first-line treatment are increasingly being tailored to histologic and molecular subtypes of advanced STS including high-dose ifosfamide in SS, ${ }^{22,23}$ gemcitabine and docetaxel in UPS or LMS (particularly uterine LMS), ${ }^{24-27}$ trabectedin in LMS or LPS (particularly myxoid/round cell LPS), ${ }^{28}$ pazopanib in all STS subtypes except LPS, ${ }^{29}$ and eribulin in LPS. ${ }^{30}$

Although doxorubicin is an effective therapy in sarcoma, its dose-dependent risk of cardiotoxicity seen with cumulative doses $300-950 \mathrm{mg} / \mathrm{m}^{2}$ remains a significant safety concern. Consequently, continuous use or rechallenge with doxorubicin is limited by the finite number of cycles that can be administered safely in the treatment course for advanced STS. Furthermore, despite the availability of therapies for
STS when standard treatments have failed (salvage therapies), prognosis remains poor in relapsed or refractory STS patients with a median OS of 8-12 months. ${ }^{21}$ The rational and clinical development of novel agents to improve outcomes in this area of high unmet need is desperately warranted. In this review, we highlight the clinical development of aldoxorubicin, a doxorubicin derivative with promising activity in the treatment of advanced STS. In particular, the pharmacokinetics (PKs), toxicity profile, and results thus far available from Phase I-III trials of aldoxorubicin in advanced STS are reviewed.

\section{Mechanism of action}

Aldoxorubicin is a prodrug of doxorubicin with acid-sensitive properties that binds covalently to serum albumin in the bloodstream and accumulates in tumors. ${ }^{31-33}$ Endogenous albumin is a potential drug carrier because it accumulates in solid tumors due to the high cell turnover, angiogenic, defective vascular architecture, and impaired lymphatic drainage characteristic of tumor tissues. ${ }^{31}$ Furthermore, the HS group of $\mathrm{Cys}^{34}$ of albumin is absent in the majority of remaining circulating serum proteins, making it an accessible functional group. ${ }^{31,33}$ Selective binding of thiol-reactive prodrugs to the $\mathrm{Cys}^{34}$ position of endogenous albumin occurring after intravenous administration that is followed by the release of the albumin-bound drug at the tumor site represents the macromolecular prodrug strategy of aldoxorubicin. ${ }^{31}$ Aldoxorubicin contains an acid-sensitive hydrazone linker that facilitates doxorubicin release either intracellularly in acidic lysosomal (or endosomal) compartments after cellular uptake of the albumin conjugate by tumor cells or extracellularly in the slightly acidic environment often present in tumor tissues. ${ }^{33}$

\section{PKs}

An early Phase I study characterized the PKs of aldoxorubicin (DOXO-EMCH or INNO-206) in 41 patients with treatmentrefractory advanced solid tumors administered aldoxorubicin 20-340 mg/m² as intravenous (IV) $30 \mathrm{~min}$ infusions during the first cycle of therapy (every 3 week cycles). ${ }^{33}$ The mean half-lives $\left(t_{1 / 2}\right)$ of DOXO-EMCH ranged from 17.6 to $38.2 \mathrm{~h}$ and were in the same order as the $t_{1 / 2}$ reported for doxorubicin $(\sim 15-40 \mathrm{~h})$. The mean peak concentrations $\left(C_{\max }\right)$ after administration of DOXO-EMCH ranged from 11.3 to $234.6 \mu \mathrm{mol} / \mathrm{L}$, and the mean area under concentration/time curve up to the last quantifiable concentration $\left(\mathrm{AUC}_{\text {all }}\right.$ ) ranged from 169.6 to $2,547 \mathrm{~h} \mu \mathrm{mol} / \mathrm{L}$ with the large AUC values representing the long circulating drug delivery system and 
the stability of DOXO-EMCH in circulation. Reported AUC values for conventional doxorubicin have been $\sim 3 \mathrm{~h} \mu \mathrm{mol} / \mathrm{L}$ for a dose of $60 \mathrm{mg} / \mathrm{m}^{2}$. There was a dose-dependent relationship between dose of DOXO-EMCH administered and $C_{\max }$ and $\mathrm{AUC}_{\text {all }}$ (except for the 150 and $180 \mathrm{mg} / \mathrm{m}^{2}$ dose groups). The mean total body clearance of doxorubicin $\left(\mathrm{Cl}_{\mathrm{obs}}\right)$ ranged from 2.15 to $3.37 \mathrm{~mL} / \mathrm{min} / \mathrm{m}^{2}$, which is significantly lower than that of conventional doxorubicin $\left(\sim 580 \mathrm{~mL} / \mathrm{min} / \mathrm{m}^{2}\right)$. There was no relationship between $\mathrm{Cl}$ and dose of DOXO$\mathrm{EMCH}$. The volume of distribution $\left(V_{\mathrm{D}}\right)$ was narrow $\left(3.96-4.08 \mathrm{~L} / \mathrm{m}^{2}\right)$ and suggests an inability of aldoxorubicin to readily accumulate in third spaces.

A later Phase I trial evaluated the PKs of a new formulation of aldoxorubicin with improved reconstitution and reduced or eliminated inactive ingredients administered as 230 or $350 \mathrm{mg} / \mathrm{m}^{2} 30 \mathrm{~min}$ infusions during cycle 1 (21-day cycles) in 18 patients with relapsed or refractory advanced solid tumors. ${ }^{32}$ Here, aldoxorubicin demonstrated a mean circulating $t_{1 / 2}$ of 20.1-21.1 h, a narrow mean $V_{\mathrm{D}}$ of $3.96-4.09 \mathrm{~L} / \mathrm{m}^{2}$, and a slow mean $\mathrm{Cl}$ of $0.136-0.152 \mathrm{~L} / \mathrm{h} / \mathrm{m}^{2}$. The mean $C_{\max }$ ranged from 67,400 to $105,000 \mathrm{ng} / \mathrm{mL}$, and only a small fraction of the plasma concentration comprised free doxorubicin and doxorubicinol (4.17-13.7 $\mathrm{ng} / \mathrm{mL})$, which suggests that almost all doxorobucin in the circulation remains bound to albumin via the acid-sensitive linker. These features suggest that aldoxorubicin is stable in circulation and is not released until exposed to an acidic environment such as that found at the tumor site. Furthermore, only trace amounts of doxorubicinol, the major metabolite of doxorubicin implicated in doxorubicin-associated cardiomyopathy, was found excreted in urine and may account for the minimal cardiotoxicity observed with aldoxorubicin treatment.

\section{Phase I trials}

There have been six Phase I trials of aldoxorubicin conducted thus far to characterize the toxicity profile, maximum tolerated dose (MTD), and preliminary efficacy (Table 1)..$^{32-37}$ In one Phase I trial of aldoxorubicin administered as 230 or $350 \mathrm{mg} / \mathrm{m}^{2} 30 \mathrm{~min}$ infusions on day 1 of every 21 -day cycle in 18 patients with relapsed or refractory advanced solid tumors, there were $11 / 22(50.0 \%)$ possibly or definitely treatment-related grades 3-4 AEs with one aldoxorubicinrelated serious $\mathrm{AE}$ of febrile neutropenia (did not receive GCSF). ${ }^{32}$ There were three partial responses (PRs): one with thyroid cancer in the $230 \mathrm{mg} / \mathrm{m}^{2}$ group who had nine cycles completed, one with mesothelioma in the $350 \mathrm{mg} / \mathrm{m}^{2}$ group, and one with small-cell lung cancer (SCLC) with an unconfirmed PR after four cycles in the $230 \mathrm{mg} / \mathrm{m}^{2}$ group.

Table I Phase I clinical trials of aldoxorubicin

\begin{tabular}{|c|c|c|c|c|c|c|}
\hline $\mathbf{n}$ & Design & Tumor histology & Doses & $\begin{array}{l}\text { Primary } \\
\text { endpoint }\end{array}$ & Results & Reference \\
\hline 18 & $\begin{array}{l}\text { Open label, } \\
\text { single-center, } \\
\text { single arm }\end{array}$ & $\begin{array}{l}\text { Various relapsed or } \\
\text { refractory advanced } \\
\text { solid tumors }\end{array}$ & $\begin{array}{l}230 \text { or } 350 \mathrm{mg} / \mathrm{m}^{2} \text { IV } 30 \mathrm{~min} \\
\text { infusion on day I every } \\
2 \text { I days }\end{array}$ & PKs & $\begin{array}{l}t_{1 / 2}: 20.1-21.1 \mathrm{~h} \\
\text { Mean } V_{\mathrm{D}}: 3.96-4.08 \mathrm{~L} / \mathrm{m}^{2} \\
\text { Mean Cl: } 0.136-0.152 \mathrm{~L} / \mathrm{h} / \mathrm{m}^{2}\end{array}$ & 32 \\
\hline 41 & $\begin{array}{l}\text { Open label, } \\
\text { single-center, } \\
\text { single arm }\end{array}$ & $\begin{array}{l}\text { Various relapsed or } \\
\text { refractory advanced } \\
\text { solid tumors }\end{array}$ & $\begin{array}{l}20-340 \mathrm{mg} / \mathrm{m}^{2} \text { IV } 30 \mathrm{~min} \\
\text { infusion on day I every } \\
2 \text { I days }\end{array}$ & $\begin{array}{l}\text { MTD } \\
\text { DLT }\end{array}$ & $\begin{array}{l}\text { MTD: } 340 \mathrm{mg} / \mathrm{m}^{2} \text { (RP2D } 260 \mathrm{mg} / \mathrm{m}^{2} \text { ) } \\
\text { DLT: myelosuppression (grades I-3) and } \\
\text { mucositis (grades I-3) }\end{array}$ & 33 \\
\hline 25 & $\begin{array}{l}\text { Open label, } \\
\text { single-center, } \\
\text { single arm }\end{array}$ & $\begin{array}{l}\text { Various relapsed or } \\
\text { refractory advanced } \\
\text { solid tumors }\end{array}$ & $\begin{array}{l}230,350 \text {, or } 450 \mathrm{mg} / \mathrm{m}^{2} \mathrm{IV} \\
30 \text { min infusion on day I } \\
\text { every } 2 \mathrm{I} \text { days }\end{array}$ & $\begin{array}{l}\text { MTD } \\
\text { DLT }\end{array}$ & $\begin{array}{l}\text { MTD: } 350 \mathrm{mg} / \mathrm{m}^{2} \\
\text { DLT: neutropenia (grade 4) and febrile } \\
\text { neutropenia (grade 3) }\end{array}$ & 34 \\
\hline 27 & $\begin{array}{l}\text { Open label, } \\
\text { single-center, } \\
\text { single arm }\end{array}$ & $\begin{array}{l}\text { Previously treated } \\
\text { or untreated } \\
\text { advanced STS }\end{array}$ & $\begin{array}{l}250 \mathrm{mg} / \mathrm{m}^{2} \text { IV on day I with } \\
\text { continuous infusion of I-M } \\
\text { days I-14 every } 28 \text { days }\end{array}$ & $\begin{array}{l}\text { Efficacy } \\
\text { Toxicity }\end{array}$ & $\begin{array}{l}42 \% \text { PR, } 58 \% \text { SD, median PFS not reached } \\
\text { Toxicities (grades } 3-4) \text { : neutropenia }(78 \%) \text {, } \\
\text { anemia }(65 \%) \text {, thrombocytopenia }(22 \%) \text {, febrile } \\
\text { neutropenia }(9 \%) \text {, no decrease in LVEF }>20 \%\end{array}$ & 35 \\
\hline 10 & $\begin{array}{l}\text { Open label, } \\
\text { single-center, } \\
\text { single arm }\end{array}$ & $\begin{array}{l}\text { Various relapsed or } \\
\text { refractory advanced } \\
\text { solid tumors }\end{array}$ & $\begin{array}{l}\text { I75, } 240 \text {, or } 320 \mathrm{mg} / \mathrm{m}^{2} \text { plus } \\
\text { doxorubicin } 35 \mathrm{mg} / \mathrm{m}^{2} \text { IV } \\
\text { both on day I every } 2 \text { I days }\end{array}$ & $\begin{array}{l}\text { MTD } \\
\text { DLT }\end{array}$ & $\begin{array}{l}\text { MTD: } 320 \mathrm{mg} / \mathrm{m}^{2} \text { aldoxorubicin and } 35 \mathrm{mg} / \mathrm{m}^{2} \\
\text { doxorubicin } \\
\text { No DLT observed }\end{array}$ & 36 \\
\hline 22 & $\begin{array}{l}\text { Open label, } \\
\text { multicenter, } \\
\text { single arm }\end{array}$ & $\begin{array}{l}\text { Various relapsed or } \\
\text { refractory advanced } \\
\text { solid tumors }\end{array}$ & $\begin{array}{l}\text { A } 170 \mathrm{mg} / \mathrm{m}^{2}+\mathrm{G} 900 \mathrm{mg} / \mathrm{m}^{2} \text {; } \\
\text { A } 250 \mathrm{mg} / \mathrm{m}^{2}+\mathrm{G} 900 \mathrm{mg} / \mathrm{m}^{2} \text {; } \\
\text { A } 200 \mathrm{mg} / \mathrm{m}^{2}+\mathrm{G} 750 \mathrm{mg} / \mathrm{m}^{2} \\
\text { (A on day I and G on days } \\
\text { I-8, every } 2 \text { I days) }\end{array}$ & $\begin{array}{l}\text { RP2D } \\
\text { DLT }\end{array}$ & $\begin{array}{l}\text { RP2D: A } 200 \mathrm{mg} / \mathrm{m}^{2}+\mathrm{G} 500 \mathrm{mg} / \mathrm{m}^{2} \\
\text { DLT: thrombocytopenia (grades 3-4) } \\
\text { Toxicities (grades } 3-4 \text { ): I } 3 \text { patients with } \\
\text { thrombocytopenia, seven patients with } \\
\text { neutropenia, eight patients with anemia, no } \\
\text { patients with LVEF }<50 \% \text { of normal }\end{array}$ & 37 \\
\hline
\end{tabular}

Abbreviations: $\mathrm{A}$, aldoxorubicin; $\mathrm{Cl}$, clearance rate; DLT, dose-limiting toxicity; G, gemcitabine; I-M, ifosfamide/mesna; IV, intravenous; LVEF, left ventricular ejection fraction; MTD, maximum-tolerated dose; PFS, progression-free survival; PKs, pharmacokinetics; PR, partial response; RP2D, recommended phase II dose; SD, stable disease; STS, soft tissue sarcoma; $t_{1 / 2}$, half-life; $V_{\mathrm{D}}$, volume of distribution. 
There were three patients with stable disease (SD) and tumor shrinkage. PKs was the primary endpoint of this study and was previously described (Table 1). An earlier open-label, dose-escalation, Phase I study administered aldoxorubicin (DOXO-EMCH) in 41 patients with treatment-refractory advanced solid tumors at $20-340 \mathrm{mg} / \mathrm{m}^{2}$ as $30-\mathrm{min}$ infusions on day 1 of every 21-day cycle to determine the MTD and dose-limiting toxicities (DLTs). ${ }^{33}$ No DLTs were observed until up to the $200 \mathrm{mg} / \mathrm{m}^{2}$ dose level where one grade 4 neutropenia occurred resulting in expansion to six patients. The MTD was defined as $340 \mathrm{mg} / \mathrm{m}^{2}$ where DLTs of mucositis and myelosuppression occurred, while the recommended phase II dose (RP2D) was $260 \mathrm{mg} / \mathrm{m}^{2}$. At $260 \mathrm{mg} / \mathrm{m}^{2}$, grades 1-2 myelosuppression and grades 1-2 mucositis were the most frequent AEs. Of the 30 evaluable patients, there were three patients with PRs $\left(180-340 \mathrm{mg} / \mathrm{m}^{2}\right)$ and 15 patients with SD.

A Phase Ib, open-label study of new formulation aldoxorubicin administered at 230,350 , or $450 \mathrm{mg} / \mathrm{m}^{2}$ on day 1 every 21 days determined that aldoxorubicin at a dose of $350 \mathrm{mg} / \mathrm{m}^{2}$ every 21 days for up to eight cycles was safe and demonstrated preliminary efficacy. ${ }^{34}$ A total of 25 patients with relapsed or refractory advanced solid tumors were enrolled, and at the $450 \mathrm{mg} / \mathrm{m}^{2}$ dose level, two patients with DLTs of grade 4 neutropenia and grade 3 febrile neutropenia were enrolled and $350 \mathrm{mg} / \mathrm{m}^{2}$ was defined as the MTD (Table 1). At the MTD, the most common grades 3-4 AE was myelosuppression with two events of febrile neutropenia $(11 \%)$ and six patients discontinued treatment due to treatment-related AEs. No patients experienced a decrease in left ventricular ejection fraction (LVEF) to $<45 \%$ of predicted. The ORR of the overall cohort was $20 \%$ (five PRs), and the median PFS was 4.80 months (95\% confidence interval [CI] 2.63-13.85) with 10 patients who experienced SD (40\%). Of the 13 patients with STS at the MTD, there were five PRs (38\%) and six patients with SD (46\%) with a median PFS of 11.25 months (95\% CI 4.80-21.71).

A separate open-label, Phase I study demonstrated that aldoxorubicin can also be administered safely with other chemotherapy agents commonly used in the treatment of STS. ${ }^{35}$ Here, aldoxorubicin administered at $250 \mathrm{mg} / \mathrm{m}^{2}$ on day 1 with continuous infusion of ifosfamide and mesna ( $1 \mathrm{~g} / \mathrm{m}^{2}$ each per day up to 14 days for a maximum of 628 -day cycles) in 27 patients with STS in the first- or second-line settings showed promising ORR with the most common AE being myelosuppression (Table 1). There were 10 patients with PR or SD who had subsequent surgery to remove accessible tumors. One open-label, dose-escalation, Phase Ib study investigated IV aldoxorubicin administered at 175, 240, or $320 \mathrm{mg} / \mathrm{m}^{2}$ with $35 \mathrm{mg} / \mathrm{m}^{2} \mathrm{IV}$ doxorubicin both on day 1 of 21-day cycles (for up to eight cycles) to determine the MTD of this combination. ${ }^{36}$ Aldoxorubicin $\left(320 \mathrm{mg} / \mathrm{m}^{2}\right)$ can be safely administered with doxorubicin $\left(35 \mathrm{mg} / \mathrm{m}^{2}\right)$ without adding further toxicity as no DLTs occurred in 10 patients with STS. No significant mucositis or cardiotoxicity was observed, but grades 3-4 AEs occurred in 8/10 patients with neutropenia, $4 / 10$ patients with thrombocytopenia, 3/10 patients with anemia, and 3/10 patients with febrile neutropenia. Although hematologic toxicity was common, it can be controlled with growth factors. The best response at the time of this study was SD in 6/10 patients and one PR in a patient with malignant fibrous histiocytoma (MFH).

Finally, a Phase Ib study showed that aldoxorubicin can be administered safely at a RP2D of IV $200 \mathrm{mg} / \mathrm{m}^{2}$ (on day 1) with gemcitabine $500 \mathrm{mg} / \mathrm{m}^{2}$ (on days 1-8) over 21-day cycles. ${ }^{37}$ Of the 22 patients with relapsed or refractory solid tumors, thrombocytopenia was the major grades 3-4 AE that was dose limiting, though 11 serious AEs were observed including Klebsiella infection, sepsis, febrile neutropenia, thrombocytopenia, anemia, stomatitis, small bowel obstruction, fever, pneumonia, pleural effusion, and urinary tract infection. Cardiac function was monitored by echocardiogram every 2 months, and no significant cardiotoxicity was observed. There were two patients with PRs (uterine LMS and ovarian cancer) and 11 patients with SD as best responses so far.

\section{Phase II trials}

In an international, multicenter, open-label, Phase IIb trial randomizing $(2: 1)$ patients with locally advanced, unresectable, and/or metastatic STS to receive first-line IV aldoxorubicin $350 \mathrm{mg} / \mathrm{m}^{2}$ or doxorubicin $75 \mathrm{mg} / \mathrm{m}^{2}$ every 21 days (up to six cycles), the primary endpoint of PFS was significantly improved with aldoxorubicin compared to doxorubicin with a 6 -month PFS rate of 46 vs $23 \%$ $(P=0.02$, Table 2$) .{ }^{38}$ The median OS was 15.8 months $(95 \%$ CI 13.0-not available) with aldoxorubicin and 14.3 months (95\% CI 8.6-20.6, hazard ratio [HR] 0.73, 95\% CI 0.44-1.20, $P=0.21$ ) with doxorubicin, though this study was not powered for OS. ORRs were also higher with aldoxorubicin compared to doxorubicin (25 vs 0\%). Grades 3-4 neutropenia was more frequent with aldoxorubicin than with doxorubicin (29 vs $12 \%$ ), but not grades 3-4 febrile neutropenia (14 vs $18 \%$ ). Treatment discontinuation due to AEs occurred in $6 \%$ in the aldoxorubicin group and $8 \%$ in the doxorubicin group. Notably, three patients in the doxorubicin group 
Table 2 Phase II clinical trials of aldoxorubicin in advanced or metastatic STS

\begin{tabular}{|c|c|c|c|c|c|c|}
\hline $\mathbf{n}$ & Design & $\begin{array}{l}\text { Experimental } \\
\text { arm }\end{array}$ & $\begin{array}{l}\text { Control } \\
\text { arm }\end{array}$ & $\begin{array}{l}\text { Primary } \\
\text { endpoint }\end{array}$ & Results & Reference \\
\hline $\begin{array}{l}\text { I } 26 \text { patients } \\
\text { with various } \\
\text { advanced } \\
\text { STS, first line }\end{array}$ & $\begin{array}{l}\text { Randomized, } \\
\text { open label, } \\
\text { multicenter }\end{array}$ & $\begin{array}{l}\text { Aldoxorubicin } \\
350 \mathrm{mg} / \mathrm{m}^{2} \mathrm{IV} \\
\text { every } 2 \mathrm{I} \text { days }\end{array}$ & $\begin{array}{l}\text { Doxorubicin } \\
75 \mathrm{mg} / \mathrm{m}^{2} \mathrm{IV} \\
\text { every } 2 \mathrm{I} \text { days }\end{array}$ & PFS & $\begin{array}{l}\text { Median PFS } 5.6 \text { months }(95 \% \mathrm{Cl} 3.0-8 . \mathrm{I}) \text { vs } \\
2.7 \text { months ( } 95 \% \mathrm{Cl} \text { I.6-4.3, } P=0.02) \\
\text { Secondary endpoints: } 6 \text {-month PFS rate ( } 46 \text { vs } 23 \% \text {, } \\
P=0.02) \text {; median } \mathrm{OS} \mathrm{I5.8} \mathrm{months}(95 \% \mathrm{Cl} \text { I } 3.0-\mathrm{NR}) \text { vs } \\
\text { I4.3 months ( } 95 \% \mathrm{Cl} 8.6-20.6, P=0.2 \mathrm{I}) \text {; ORR } 25 \text { vs } 0 \%\end{array}$ & 38 \\
\hline $\begin{array}{l}\text { Nine patients } \\
\text { with AIDS- } \\
\text { related KS, } \\
\text { first line and } \\
\text { second line }\end{array}$ & $\begin{array}{l}\text { Randomized, } \\
\text { open label, } \\
\text { single-center }\end{array}$ & $\begin{array}{l}\text { Aldoxorubicin } \\
50,100, \text { or } \\
150 \mathrm{mg} / \mathrm{m}^{2} \mathrm{IV} \\
\text { every } 2 \text { I days }\end{array}$ & None & $\begin{array}{l}\text { Safety } \\
\text { Efficacy }\end{array}$ & $\begin{array}{l}\text { I/9 patients with grade } 4 \text { neutropenia at } 100 \mathrm{mg} / \mathrm{m}^{2} \\
4 / 6 \text { patients responded } \\
\text { I patient progressed } \\
6 / 9 \text { patients exhibited reductions in } \mathrm{KSHV} \text { genome } \\
\text { copies/cell }\end{array}$ & 39 \\
\hline
\end{tabular}

Abbreviations: $\mathrm{Cl}$, confidence interval; IV, intravenous; KS, Kaposi sarcoma; KSHV, KS herpes virus; NR, not reported; ORR, overall response rate; OS, overall survival; PFS, progression-free survival; STS, soft tissue sarcomas.

vs none in the aldoxorubicin group experienced LVEF that decreased $<50 \%$ of normal. Overall, the total number of patients who experienced a LVEF decrease of $\geq 10 \%$ was nine (12\%) with aldoxorubicin and $11(29 \%)$ with doxorubicin.

Aldoxorubicin is also an active drug for the treatment of HIV-associated Kaposi sarcoma (Table 2).$^{39}$ In this Phase II, open-label trial, IV aldoxorubicin as first- or second-line treatment was administered as 50,100 , or $150 \mathrm{mg} / \mathrm{m}^{2}$ every 3 weeks in patients with advanced HIV-associated Kaposi sarcoma. Only one of the nine patients experienced grade 4 neutropenia at the $100 \mathrm{mg} / \mathrm{m}^{2}$ dose level, $4 / 6$ patients experienced initial response, and 6/9 patients showed significant reductions in Kaposi sarcoma herpes virus genome copies per cell. Of note, four patients had received prior Doxil chemotherapy.

\section{Phase III trials}

In a pivotal international, multicenter, Phase III trial evaluating PFS as the primary endpoint, 433 patients with relapsed or refractory STS were randomly assigned to receive IV aldoxorubicin $350 \mathrm{mg} / \mathrm{m}^{2}\left(260 \mathrm{mg} / \mathrm{m}^{2}\right.$ doxorubicin equivalent) every 3 weeks or investigator's choice of treatment (IC) including dacarbazine, doxorubicin, pazopanib, ifosfamide, and gemcitabine/docetaxel with GCSF support. ${ }^{40}$ Tumor subtypes included LMS (42.2\%), LPS (12.8\%), SS (9.6\%), and other sarcomas (34.9\%). Approximately two-thirds of the patients received prior doxorubicin in both experimental and control arms. The mean cumulative doxorubicin equivalent dose of aldoxorubicin administered was $1,359.8 \mathrm{mg} / \mathrm{m}^{2}$ (range 260-10,920). Aldoxorubicin demonstrated superior median PFS over IC in patients with LMS or LPS (L-sarcomas) and in patients enrolled in North America (Table 3). In the overall cohort, median PFS was not significantly different between aldoxorubicin and IC arms. Secondary endpoints included ORR, disease control rate (DCR), OS, and safety. Although the ORR was twice as high in the aldoxorubicin $\operatorname{arm}(8.3$ vs $4.2 \%, P=0.1106)$, there was no significant difference in median OS (12.88 months, $95 \%$ CI $10.05-15.11$ vs

Table 3 Phase III clinical trial of aldoxorubicin in advanced or metastatic STS

\begin{tabular}{|c|c|c|c|c|c|c|}
\hline $\mathbf{n}$ & Design & $\begin{array}{l}\text { Experimental } \\
\text { arm }\end{array}$ & $\begin{array}{l}\text { Control } \\
\text { arm }\end{array}$ & $\begin{array}{l}\text { Primary } \\
\text { endpoint }\end{array}$ & Results & Reference \\
\hline $\begin{array}{l}433 \text { patients with } \\
\text { various relapsed } \\
\text { or refractory } \\
\text { advanced STS, } \\
\text { second-line }\end{array}$ & $\begin{array}{l}\text { Randomized } \\
(I: I), \\
\text { open label, } \\
\text { multicenter }\end{array}$ & $\begin{array}{l}\text { Aldoxorubicin } \\
350 \mathrm{mg} / \mathrm{m}^{2} \mathrm{IV} \\
\text { every } 2 \text { I days }\end{array}$ & IC & PFS & 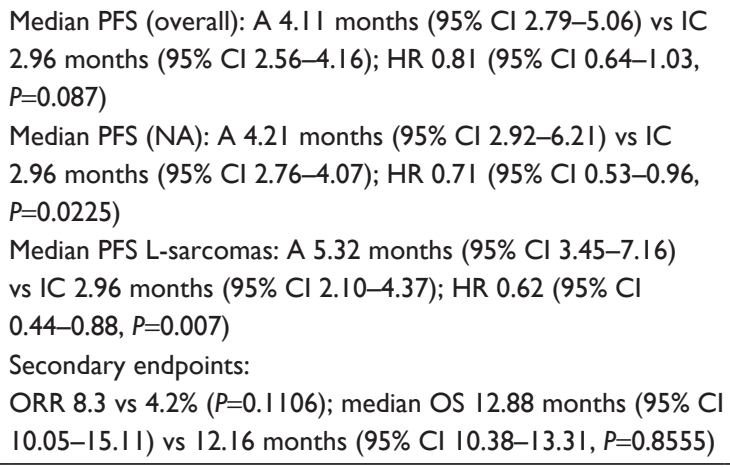 & 40 \\
\hline
\end{tabular}

Abbreviations: $\mathrm{A}$, aldoxorubicin; $\mathrm{Cl}$, confidence interval; $\mathrm{HR}$, hazard ratio; IC, investigator's choice of treatment; NA, North America; ORR, overall response rate; OS, overall survival; PFS, progression-free survival; STS, soft tissue sarcomas; L-sarcoma, liposarcoma or leiomyosarcoma. 
12.16 months, 95\% CI 10.38-13.31, $P=0.8555)$. There was a trend toward significantly improved ORR in the L-sarcomas cohort treated with aldoxorubicin (10.0 vs $4.0 \%, P=0.0790)$ compared to IC. In the intent-to-treat population, the DCR was $33.5 \%$ with aldoxorubicin vs $25.1 \%$ with IC ( $P=0.0583)$. This achieved statistical significance in patients with L-sarcomas (41.7 vs $27.0 \%, P=0.0161$ ). Of the 213 patients randomized to aldoxorubicin and 207 patients randomized to IC, treatment-related AEs leading to study drug discontinuation was observed in 8.9 and $6.8 \%$, respectively. There were more grade $\geq 3$ AEs (74.2 vs $64.3 \%$ ), grade $\geq 3$ treatmentrelated AEs (64.3 vs 46.9\%), serious AEs (42.7 vs 32.9\%), and treatment-related AEs resulting in death (1.4 vs $0 \%)$ in the aldoxorubicin arm. The most common grade $\geq 3$ AEs ( $\geq 5 \%$ ) were neutropenia (23.9\%), anemia (22.1\%), febrile neutropenia (15.5\%), and stomatitis (15.5\%) in the aldoxorubicin arm and anemia (13.5\%), neutropenia (11.6\%), and thrombocytopenia in the IC arm. Cardiac toxicity, defined by $>20 \%$ decrease in $\mathrm{LVEF}$, was lower in patients receiving aldoxorubicin compared to those in the IC arm receiving doxorubicin (3.8 vs 8.5\%). There were fewer patients with LVEF $<50 \%$ of any postbaseline visit in the aldoxorubicin arm as well (4.2 vs 19.1\%). Interestingly, no alopecia was noted in the aldoxorubicin group. In summary, aldoxorubicin was associated with a superior PFS compared with standard of care (SOC) regimens in North America and L-sarcomas suggesting that it may be the superior anthracycline compared to doxorubicin in advanced STS. Furthermore, aldoxorubicin represents a viable alternative compared to SOC in patients with relapsed or refractory metastatic STS.

\section{Discussion}

Salvage therapies in advanced or metastatic STS after initial or first-line treatment have been shown to confer an absolute benefit in OS and PFS by 3.3 and 1.6 months, respectively, and a near doubling of ORR when compared with control. ${ }^{21}$ Furthermore, survival after failure of first-line therapy accounts for $>70 \%$ of the entire OS despite postprogression therapies and crossover to other agents that may potentially dilute the absolute gain - altogether highlighting the activity of new agents even in treatment-refractory STS. ${ }^{21}$ However, despite these advances in therapies after initial treatment of advanced STS, prognosis remains dismal with a median OS of 8-12 months. ${ }^{21}$ To this end, aldoxorubicin shows promise in fulfilling an unmet need for effective treatments in relapsed or refractory advanced STS. ${ }^{41}$

Aldoxorubicin has shown activity in first-line and beyond settings in advanced STS with the most common DLT being myelosuppression that can be reasonably controlled with GCSF support (Tables 1-3). Its PKs is characterized by a slow $\mathrm{Cl}$ and narrow $V_{\mathrm{D}}$ supporting its low tendency to accumulate in third spaces and an albumin conjugate tumor targeting design that ensures its stability in the circulation where almost all doxorobucin remains bound to albumin until exposed to the acidic environment of tumor tissues. Furthermore, only trace amounts of doxorubicinol, the major metabolite of doxorubicin implicated in doxorubicinassociated cardiomyopathy, are found excreted in urine and may account for the minimal cardiotoxicity observed with aldoxorubicin treatment. ${ }^{32,33}$

In the largest study to date that demonstrated superior PFS with aldoxorubicin over doxorubicin in the first-line treatment of advanced STS, aldoxorubicin produced a median PFS of 5.6 months (95\% CI 3.0-8.1), OS of 15.8 months (95\% CI 13.0-not reached), and ORR of 25\%. ${ }^{38}$ Notably, OS was not significantly different between aldoxorubicin and doxorubicin, though this study was not powered for OS. ${ }^{38}$ As a comparison to historical standard first-line therapies, the combination of doxorubicin and ifosfamide produced a median PFS range of 7.3-7.4 months, OS range of 13.8-14.3 months, and ORR range of 23.3-26\% across two large, randomized Phase III studies in advanced STS. ${ }^{13,14}$ In the Phase Ib/II trial that led to the approval of doxorubicin and olaratumab in the first-line treatment of advanced STS, the combination resulted in a median PFS of 6.6 months (95\% CI 4.1-8.3), OS of 26.5 months (95\% CI 20.9-31.7), and ORR of $18.2 \%$ (95\% CI 9.8-29.6). ${ }^{17}$ The median PFS and ORR observed with aldoxorubicin are comparable to those observed with doxorubicin/ifosfamide and doxorubicin/ olaratumab in the first-line treatment of advanced STS. ${ }^{13,17,38}$ The median OS with aldoxorubicin is comparable with that of doxorubicin and ifosfamide but lower than the median OS seen in the doxorubicin and olaratumab study. ${ }^{13,14,17,38}$ Great caution should be taken in these historical comparisons, however, as differences in study design, patient characteristics, and disease biology can significantly influence the interpretability of such cross-study comparisons. For example, the median PFS (2.7 months, 95\% CI 1.6-4.3) and the median ORR $(0 \%)$ in the doxorubicin control arm of the aldoxorubicin study are lower than those in the doxorubicin control arms of the doxorubicin/olaratumab (median PFS 4.1 months, 95\% CI 2.8-5.4; ORR 11.9\%) and doxorubicin/ifosfamide (median PFS 4.6 months, 95\% CI 2.9-5.6; ORR 14\%) studies that suggest the presence of heterogeneity across study populations. ${ }^{13,17,38}$ Ultimately, the comparison of the efficacy of aldoxorubicin with current standards in 
the first-line treatment of advanced STS would be best served in the setting of a large, randomized, and adequately powered prospective study. There are currently no ongoing clinical trials investigating such comparisons, but studies of this nature are certainly warranted to elucidate the role of aldoxorubicin in the first-line treatment of unresectable or metastatic STS.

In the relapsed or refractory setting, the efficacy of aldoxorubicin was directly compared with standard therapies including dacarbazine, doxorubicin, pazopanib, ifosfamide, and gemcitabine/docetaxel in patients with previously treated advanced STS. In this pivotal Phase III trial, aldoxorubicin showed superior PFS to IC in relapsed or refractory advanced STS in prespecified analyses of the North American (vs European Union) and L-sarcoma (vs other sarcomas) cohorts. $^{40}$ Notably, a majority of $68.4 \%$ of patients were enrolled into the North American cohort and the distribution of L-sarcomas in this cohort was not reported. Heterogeneity in sarcoma subtypes across cohorts may, in part, explain the geographical differences observed in PFS seen with aldoxorubicin compared to doxorubicin. The lack of OS difference in this trial compared to IC in the overall cohort is unclear, and final mature OS results are eagerly awaited as well as commentary on degree of patient cross-over.

Aldoxorubicin has also shown superior safety with respect to cardiotoxicity in animals and humans. ${ }^{32,33,42}$ Although doxorubicin is an effective treatment in sarcoma, its benefits are often limited by the dose-dependent risk of cardiotoxicity. This risk of cardiotoxicity has been shown to be attributable to the metabolism of doxorubicin to doxorubicinol and its effects on cardiac tissue. ${ }^{43,44}$ Very low levels of the metabolite doxorubicinol are excreted in the urine following aldoxorubicin administration, perhaps explaining the lack of cardiotoxicity associated with aldoxorubicin. ${ }^{32}$ When DOXO-EMCH (aldoxorubicin) is administered in rats at doses of 1.1 and $3.3 \mathrm{mg} / \mathrm{kg}$ compared to doxorubicin $(0.8 \mathrm{mg} / \mathrm{kg}$ weekly for 7 weeks $)$, both DOXOEMCH groups did not differ from controls that received saline in regard to clinical symptomatology, mortality, and mitochondrial enzymes associated with cardiomyopathy. The doxorubicin-exposed rats, however, had severe clinical and histopathological cardiomyopathies with associated parameters correlated with myocardial damage. ${ }^{42}$ As a result, several fold higher doses of aldoxorubicin can be administered with cumulative doses $\left(>2,000 \mathrm{mg} / \mathrm{m}^{2}\right)$ of doxorubicin equivalents and have been achieved without the associated cardiotoxicity typically seen with cumulative doxorubicin doses $300-950 \mathrm{mg} / \mathrm{m}^{2} .34,38$
The long-term cardiac safety profile of aldoxorubicin has been shown by reviewing data from three Phase I studies and one Phase IIB study (142 patients). ${ }^{45}$ All patients had normal cardiac function at baseline. The dose range of aldoxorubicin was $175-350 \mathrm{mg} / \mathrm{m}^{2}$ administered IV every 3 weeks (equivalent to $130-260 \mathrm{mg} / \mathrm{m}^{2}$ doxorubicin per cycle). Prior exposure of up to $225 \mathrm{mg} / \mathrm{m}^{2}$ of doxorubicin was allowed. Of the 126 evaluable patients who received 1-21 cycles of aldoxorubicin, no patients developed a decrease in LVEF $<50 \%$ of their institution's normal value. Only $14 \%$ developed a $\geq 10 \%$ decrease in LVEF, while $21 \%$ had an increase in LVEF. When reported, only $3.9 \%$ of patients developed a prolonged QTc $>500 \mathrm{~ms}$. No patients developed troponin elevation. Although patients received up to $5,439 \mathrm{mg} / \mathrm{m}^{2}$ of doxorubicin equivalents, or 12 times the peak cumulative dose of standard doxorubicin, there was no evidence of cardiotoxicity, thereby highlighting its superior cardiac profile.

In the recent Phase III trial, aldoxorubicin (up to 40 cycles) had minimal or no cardiotoxicity compared to doxorubicin..$^{40}$ This protocol was amended to allow aldoxorubicin administration until disease progression or unacceptable toxicities occurred. Interestingly, reduced alopecia was noted with aldoxorubicin and even no evidence of alopecia in a patient receiving up to 20 cycles. Approximately two-thirds of these patients were previously treated with doxorubicin suggesting that resistance may be overcome with a different method of delivery. PEGylated liposomal doxorubicin is more firmly established in the treatment of ovarian cancer, multiple myeloma, and AIDS-related Kaposi sarcoma and also has a relatively favorable toxicity profile compared to conventional doxorubicin. ${ }^{46}$ Although liposomal doxorubicin at $50 \mathrm{mg} / \mathrm{m}^{2}$ every 4 weeks was shown to have significantly lower risk of LVEF-defined cardiotoxicity compared to doxorubicin, clinically significant changes in LVEF were seen in $15 \%$ of patients receiving a cumulative liposomal doxorubicin dose of $>400 \mathrm{mg} / \mathrm{m}^{2}$ in a separate pooled analysis. ${ }^{46}$ Furthermore, several single-arm Phase II studies of liposomal doxorubicin in untreated and treatment-refractory advanced STS have shown mixed results on efficacy. ${ }^{19,47,48}$ In a head-to-head Phase II study, liposomal doxorubicin was shown to have equivalent activity to doxorubicin in advanced or metastatic STS. ${ }^{18}$ Taking into consideration the available clinical and safety data to date, aldoxorubicin may represent the superior anthracycline compared to doxorubicin in the treatment of advanced STS. Aldoxorubicin is also a good alternative to standard therapies for the treatment of relapsed or refractory metastatic STS. Aldoxorubicin has 
also demonstrated tolerability and activity in combination with other chemotherapy agents in STS; in one study, aldoxorubicin was combined with doxorubicin with no DLTs and additional cardiotoxicity observed..$^{35,36}$

Future directions of study for this agent will likely involve its incorporation into combination regimens with other chemotherapies, particularly in those with nonoverlapping toxicities to optimize antitumor activity. Notably, there are several trials exploring combination therapy including aldoxorubicin that are ongoing or for which final results are eagerly awaited (NCT01673438, NCT02235701, NCT02235688, NCT02200757). Future trials are warranted exploring aldoxorubicin's antitumor activity in other tumor types besides STS - several clinical trials are ongoing or for which final results are pending (NCT01580397, NCT02200757, and NCT02014844). Given its superior PFS to doxorubicin, one questions whether aldoxorubicin in combination with olaratumab would provide superior efficacy to the recently FDA-approved combination of doxorubicin and olaratumab in advanced STS. ${ }^{17}$ Aldoxorubicin provides proof-of-principle that binding an active chemotherapy compound to serum albumin can enhance efficacy without significantly increasing toxicity, and this concept warrants further development with other systemic agents in cancer therapy. Aldoxorubicin can also augment use in anticancer regimens conventionally relying on doxorubicin (such as breast and gynecologic cancers) given its ability to allow higher cumulative doses with minimal cardiotoxicities.

\section{Conclusion}

Aldoxorubicin is a tumor-targeting albumin conjugate prodrug of doxorubicin that has shown promising antitumor activity in the first-line and beyond treatment of advanced STS. In the Phase II setting, aldoxorubicin showed superior PFS compared to doxorubicin in the first-line treatment of advanced STS. In a recent Phase III trial, aldoxorubicin demonstrated superior PFS to IC in relapsed or refractory STS. Aldoxorubicin also has a superior safety profile than doxorubicin with respect to cardiotoxicity allowing higher cumulative doses with minimal cardiotoxicity. Taken together, aldoxorubicin may represent the superior anthracycline in the treatment of advanced STS. Aldoxorubicin represents a viable alternative to standard therapies in the treatment of relapsed or refractory STS. Mature and final OS results in the Phase III setting are awaited, and further investigation of aldoxorubicin in combination therapy and in other tumor types is warranted.

\section{Disclosure}

The authors report no conflicts of interest in this work.

\section{References}

1. In GK, Hu JS, Tseng WW. Treatment of advanced, metastatic soft tissue sarcoma: latest evidence and clinical considerations. Ther $A d v$ Med Oncol. 2017;9(8):533-550.

2. Siegel RL, Miller KD, Jemal A. Cancer statistics, 2017. CA Cancer J Clin. 2017;67(1):7-30.

3. Blay JY, El Sayadi H, Thiesse P, Garret J, Ray-Coquard I. Complete response to imatinib in relapsing pigmented villonodular synovitis/ tenosynovial giant cell tumor (PVNS/TGCT). Ann Oncol. 2008;19(4): 821-822.

4. Casali PG, Zalcberg J, Le Cesne A, et al. Ten-year progression-free and overall survival in patients with unresectable or metastatic GI stromal tumors: long-term analysis of the European Organisation for Research and Treatment of Cancer, Italian Sarcoma Group, and Australasian Gastrointestinal Trials Group intergroup phase III randomized trial on imatinib at two dose levels. J Clin Oncol. 2017;35(15):1713-1720.

5. DeVito N, Henderson E, Han G, et al. Clinical characteristics and outcomes for solitary fibrous tumor (SFT): a single center experience. PLoS One. 2015;10(10): 0140362.

6. Dufresne A, Cassier P, Couraud L, et al. Desmoplastic small round cell tumor: current management and recent findings. Sarcoma. 2012;2012: 714986.

7. Kummar S, Allen D, Monks A, et al. Cediranib for metastatic alveolar soft part sarcoma. J Clin Oncol. 2013;31(18):2296-2302.

8. Rutkowski P, Van Glabbeke M, Rankin CJ, et al. Imatinib mesylate in advanced dermatofibrosarcoma protuberans: pooled analysis of two phase II clinical trials. J Clin Oncol. 2010;28(10):1772-1779.

9. Schuetze SM, Bolejack V, Choy E, et al. Phase 2 study of dasatinib in patients with alveolar soft part sarcoma, chondrosarcoma, chordoma, epithelioid sarcoma, or solitary fibrous tumor. Cancer. 2017;123(1): 90-97.

10. Sethi TK, Keedy VL. Histology-specific uses of tyrosine kinase inhibitors in non-gastrointestinal stromal tumor sarcomas. Curr Treat Options Oncol. 2016;17(2):11

11. Stacchiotti S, Negri T, Zaffaroni N, et al. Sunitinib in advanced alveolar soft part sarcoma: evidence of a direct antitumor effect. Ann Oncol. 2011; 22(7):1682-1690.

12. Wagner AJ, Malinowska-Kolodziej I, Morgan JA, et al. Clinical activity of mTOR inhibition with sirolimus in malignant perivascular epithelioid cell tumors: targeting the pathogenic activation of mTORC1 in tumors. J Clin Oncol. 2010;28(5):835-840.

13. Judson I, Verweij J, Gelderblom H, et al. Doxorubicin alone versus intensified doxorubicin plus ifosfamide for first-line treatment of advanced or metastatic soft-tissue sarcoma: a randomised controlled phase 3 trial. Lancet Oncol. 2014;15(4):415-423.

14. Le Cesne A, Judson I, Crowther D, et al. Randomized phase III study comparing conventional-dose doxorubicin plus ifosfamide versus high-dose doxorubicin plus ifosfamide plus recombinant human granulocyte-macrophage colony-stimulating factor in advanced soft tissue sarcomas: a trial of the European Organization for Research and Treatment of Cancer/Soft Tissue and Bone Sarcoma Group. J Clin Oncol. 2000;18(14):2676-2684.

15. Verma S, Younus J, Stys-Norman D, Haynes AE, Blackstein M; Members of the Sarcoma Disease Site Group of Cancer Care Ontario's Program in Evidence-Based Care. Meta-analysis of ifosfamide-based combination chemotherapy in advanced soft tissue sarcoma. Cancer Treat Rev. 2008;34(4):339-347.

16. Verma S, Younus J, Stys-Norman D, Haynes AE, Blackstein M; Sarcoma Disease Site Group of Cancer Care Ontario's Program in Evidence-based Care. Dose-intensive chemotherapy with growth factor or autologous bone marrow/stem cell transplant support in firstline treatment of advanced or metastatic adult soft tissue sarcoma: a systematic review. Cancer. 2008;112(6):1197-1205. 
17. Tap WD, Jones RL, Van Tine BA, et al. Olaratumab and doxorubicin versus doxorubicin alone for treatment of soft-tissue sarcoma: an openlabel phase $1 \mathrm{~b}$ and randomised phase 2 trial. Lancet. 2016;388(10043): 488-497.

18. Judson I, Radford JA, Harris M, et al. Randomised phase II trial of pegylated liposomal doxorubicin (DOXIL/CAELYX) versus doxorubicin in the treatment of advanced or metastatic soft tissue sarcoma: a study by the EORTC Soft Tissue and Bone Sarcoma Group. Eur J Cancer. 2001;37(7):870-877.

19. Skubitz KM. Phase II trial of pegylated-liposomal doxorubicin (Doxil) in sarcoma. J Cancer Invest. 2003;21(2):167-176.

20. Sleijfer S, Seynaeve C, Verweij J. Using single-agent therapy in adult patients with advanced soft tissue sarcoma can still be considered standard care. Oncologist. 2005;10(10):833-841.

21. Comandone A, Petrelli F, Boglione A, Barni S. Salvage therapy in advanced adult soft tissue sarcoma: a systematic review and metaanalysis of randomized trials. Oncologist. 2017;22(12):1518-1527.

22. Noujaim J, Constantinidou A, Messiou C, et al. Successful ifosfamide rechallenge in soft-tissue sarcoma. Am J Clin Oncol. 2018;41(2): 147-151.

23. Rosen G, Forscher C, Lowenbraun S, et al. Synovial sarcoma. Uniform response of metastases to high dose ifosfamide. Cancer. 1994; 73(10):2506-2511

24. Hensley ML, Maki R, Venkatraman E, et al. Gemcitabine and docetaxel in patients with unresectable leiomyosarcoma: results of a phase II trial. J Clin Oncol. 2002;20(12):2824-2831.

25. Maki RG, Wathen JK, Patel SR, et al. Randomized phase II study of gemcitabine and docetaxel compared with gemcitabine alone in patients with metastatic soft tissue sarcomas: results of sarcoma alliance for research through collaboration study 002 [corrected]. J Clin Oncol. 2007;25(19):2755-2763.

26. Pautier P, Floquet A, Penel N, et al. Randomized multicenter and stratified phase II study of gemcitabine alone versus gemcitabine and docetaxel in patients with metastatic or relapsed leiomyosarcomas: a Federation Nationale des Centres de Lutte Contre le Cancer (FNCLCC) French Sarcoma Group Study (TAXOGEM study). Oncologist. 2012; 17(9):1213-1220.

27. Hensley ML, Blessing JA, Degeest K, Abulafia O, Rose PG, Homesley HD. Fixed-dose rate gemcitabine plus docetaxel as second-line therapy for metastatic uterine leiomyosarcoma: a Gynecologic Oncology Group phase II study. Gynecol Oncol. 2008;109(3):323-328.

28. Demetri GD, von Mehren M, Jones RL, et al. Efficacy and safety of trabectedin or dacarbazine for metastatic liposarcoma or leiomyosarcoma after failure of conventional chemotherapy: results of a phase III randomized multicenter clinical trial. J Clin Oncol. 2016; 34(8):786-793.

29. van der Graaf WT, Blay JY, Chawla SP, et al. Pazopanib for metastatic soft-tissue sarcoma: a randomised, double-blind, placebo-controlled phase 3 trial. Lancet. 2012;379(9829):1879-1886.

30. Schöffski P, Chawla S, Maki RG, et al. Eribulin versus dacarbazine in previously treated patients with advanced liposarcoma or leiomyosarcoma: a randomised, open-label, multicentre, phase 3 trial. Lancet. 2016;387(10028):1629-1637.

31. Kratz F, Warnecke A, Scheuermann K, et al. Probing the cysteine-34 position of endogenous serum albumin with thiol-binding doxorubicin derivatives. Improved efficacy of an acid-sensitive doxorubicin derivative with specific albumin-binding properties compared to that of the parent compound. J Med Chem. 2002;45(25):5523-5533.
32. Mita MM, Natale RB, Wolin EM, et al. Pharmacokinetic study of aldoxorubicin in patients with solid tumors. Invest New Drugs. 2015; 33(2):341-348.

33. Unger C, Häring B, Medinger M, et al. Phase I and pharmacokinetic study of the (6-maleimidocaproyl)hydrazone derivative of doxorubicin. Clin Cancer Res. 2007;13(16):4858-4866.

34. Chawla SP, Chua VS, Hendifar AF, et al. A phase $1 \mathrm{~B} / 2$ study of aldoxorubicin in patients with soft tissue sarcoma. Cancer. 2015;121(4): $570-579$.

35. Eilber FC, Sankhala KK, Chawla SP, et al. Administration of aldoxorubicin and 14 days continuous infusion of ifosfamide/mesna in metastatic or locally advanced sarcomas [abstract]. J Clin Oncol. 2017; 35(15_suppl):11051.

36. Sankhala KK, Chawla SP, Chua VS, et al. Phase Ib trial of combining aldoxorubicin plus doxorubicin [abstract]. J Clin Oncol. 2013; 31(15_suppl):2550.

37. Sankhala KK, Chawla S, Chua VS, et al. Phase 1 b study of aldoxorubicin + gemcitabine in metastatic solid tumors [abstract]. J Clin Oncol. 2016;34(15_suppl):2523.

38. Chawla SP, Papai Z, Mukhametshina G, et al. First-line aldoxorubicin vs doxorubicin in metastatic or locally advanced unresectable softtissue sarcoma: a phase $2 \mathrm{~b}$ randomized clinical trial. JAMA Oncol. 2015;1(9):1272-1280.

39. Parsons C, Chawla S, Dinh H, et al. Treatment of HIV-associated Kaposi's sarcoma with aldoxorubicin [abstract]. J Clin Oncol. 2015; 33(15_suppl):e21526.

40. Chawla SP, Ganjoo KN, Schuetze S, et al. Phase III study of aldoxorubicin vs investigators' choice as treatment for relapsed/refractory soft tissue sarcomas [abstract]. J Clin Oncol. 2017;35(15_suppl):11000.

41. Chugh R, Schuetze SM. Aldoxorubicin in sarcoma: teaching an old drug new tricks. JAMA Oncol. 2015;1(9):1280-1281.

42. Lebrecht D, Geist A, Ketelsen UP, et al. The 6-maleimidocaproyl hydrazone derivative of doxorubicin (DOXO-EMCH) is superior to free doxorubicin with respect to cardiotoxicity and mitochondrial damage. Int J Cancer. 2007;120(4):927-934.

43. Boucek RJ, Olson RD, Brenner DE, Ogunbunmi EM, Inui M, Fleischer S. The major metabolite of doxorubicin is a potent inhibitor of membraneassociated ion pumps. A correlative study of cardiac muscle with isolated membrane fractions. J Biol Chem. 1987;262:15851-15856.

44. Del Tacca M, Danesi R, Ducci M, Bernardini C, Romanini A. Might adriamycinol contribute to adriamycin-induced cardiotoxicity? Pharmacol Res Commun. 1985;17:1073-1084.

45. Chawla SP, Sankhala K, Wieland S, Levitt DJ. Longer term cardiac safety of aldoxorubicin [abstract]. J Clin Oncol. 2015;33(15_suppl):10546.

46. Lyseng-Williamson KA, Duggan ST, Keating GM. Pegylated liposomal doxorubicin: a guide to its use in various malignancies. BioDrugs. 2013;27(5):533-540.

47. Poveda A, López-Pousa A, Martín J, et al. Phase II clinical trial with pegylated liposomal doxorubicin (CAELYX(R)/Doxil(R)) and quality of life evaluation (EORTC QLQ-C30) in adult patients with advanced soft tissue sarcomas: a study of the Spanish Group for Research in Sarcomas. Sarcoma. 2005;9(3-4):127-132.

48. Chidiac T, Budd GT, Pelley R, et al. Phase II trial of liposomal doxorubicin (Doxil@) in advanced soft tissue sarcomas. Invest New Drugs. 2000;18:253-259. 


\section{Publish your work in this journal}

Drug Design, Development and Therapy is an international, peerreviewed open-access journal that spans the spectrum of drug design and development through to clinical applications. Clinical outcomes, patient safety, and programs for the development and effective, safe, and sustained use of medicines are the features of the journal, which

has also been accepted for indexing on PubMed Central. The manuscript management system is completely online and includes a very quick and fair peer-review system, which is all easy to use. Visit http://www.dovepress.com/testimonials.php to read real quotes from published authors.

Submit your manuscript here: http://www.dovepress.com/drug-design-development-and-therapy-journal 